\title{
DESEJAR CONHECER, AMAR CONHECENDO: UM EXCURSUS NOS DIALOGHI D'AMORE DE LEÃO HEBREU
}

Fran de Oliveira Alavina*

\section{Resumo:}

Elemento universal e unitivo na ordem ontológica, o amor alcança no pensamento de Leão Hebreu o posto de elemento metafísico primaz. Daí, a necessidade não apenas de elaborar uma filosofia sobre o amor, mas de estabelecer uma amorosa filosofia. Ora, a constituição de uma amorosa filosofia implica necessariamente uma consideração sobre o conhecer, não sem relação com o amor e o desejo. Já na abertura dos Dialoghi d'amore, identifica-se uma relação direta entre conhecer e amar. Fílon afirma que quanto mais conhece, mais ama e deseja. Por conseguinte, em princípio, é possível afirmar que conhecimento e amor se implicam mutuamente. Todavia, ainda que levado à exaustão, o conhecimento não encontra plenitude, pois não estabelece unicidade completa. Ainda que perfeito e completo, o intelecto atualizando ao máximo sua forma no ato contemplativo do ser sumamente perfeito não efetiva a unidade absoluta, posto que persiste a divisão entre cognoscente e cognoscível. Somente o amor, como elemento metafísico comum à constituição dos entes e possuindo a capacidade unitiva como sua essência, é capaz de realizar a unidade absoluta. Desse modo, no amor se apresenta um tipo de conhecimento unitivo perfeito. Portanto, pode-se afirmar que nos Dialoghi d'amore postula-se uma concepção do conhecimento como atividade intelectual não desprovida de primado afetivo: tal é a hipótese interpretativa sustentada.

Palavras-Chave: Desejo. Conhecimento. Amor.

\section{I) Um pensador hebraico no Renascimento: recepção e tradição interpretativa dos Dialoghi d'amore}

Ainda que preponderando para os Dialoghi uma inserção na tradição filosófica de matriz platônica, sem, contudo, desconsiderar o efetivo interesse que a obra alcançou em breve espaço de tempo ${ }^{1}$, destacando-se entre os tratados de amore no Renascimento, a obra de Leão Hebreu (1460-?), quer entre os estudiosos renascentistas, quer entre os

\footnotetext{
*Aluno do Programa de Pós-Graduação em Filosofia da USP, nível doutorado, sob a orientação do Prof. Dr. Luís César Guimarães Oliva. Este trabalho faz parte do projeto de pesquisa intitulado: Espinosa, leitor de Leão Hebreu: um estudo sobre o Breve Tratado; financiado pela FAPESP.

${ }^{1}$ Sobre a recepção e edição dos Dialoghi, ver aqui: CARVALHO, J. Leão Hebreu, Filósofo. Para a história do platonismo no Renascimento. In: Obras Completas. Vol. I. Filosofia e História da Filosofia. Lisboa: Fundação Calouste Gulbenkian, 1992; BARATA-MOURA, J. Leão Hebreu e o sentido do amor universal. In: Estudos de Filosofia Portuguesa. Lisboa: Editorial Caminho, 1998.
} 
historiadores da Filosofia, permaneceu carente de uma tradição interpretativa própria, que objetivasse inquirir suas fontes filosóficas, bem como explicitasse o novo tratamento dispensado pelo autor hebreu às questões herdadas de pensadores medievais.

Ademais, em relação aos renascentistas florentinos (em particular, Ficino e Pico della Mirandola) ${ }^{2}$, Leão Hebreu é frequentemente identificado como continuador destes, porém imputando-se à sua elaboração filosófica falta de originalidade e de rigor. Daí, correntemente ser apontado entre aqueles renascentistas que, transitando entre a Filosofia e os studia humanitatis ${ }^{3}$, teria se perdido em construções especulativas híbridas. Consequência de sua orientação metódica, que privilegiando uma multiplicidade de vias, não foi capaz de fundamentar, ao final, uma segura e precisa convergência de tradições ${ }^{4}$.

Contudo mesmo que não totalmente encerrado o debate acerca da originalidade da filosofia de Leão Hebreu, não se pode desconsiderar seu ineditismo, entre os renascentistas, ao conceber um tratado filosófico em forma de diálogo, não sendo mero comentário da concepção amorosa platônica. Trata-se, em verdade, da tentativa de reunir as diversas tradições filosóficas que apresentaram uma definição do amor como elemento metafísico singular ${ }^{5}$. Resultando do exame de tais tradições a identificação da essência do amor como gozo unitivo. Definição convergente do amor nascida do diálogo, isto é, resultante do jogo amoroso ${ }^{6}$ entre Fílon e Sofia. Desse modo, o saber não é concebido apenas como aquisição de conhecimento, mas tal qual uma relação de sedução e conquista entre amantes, na qual o objeto de conhecimento torna-se objeto amoroso.

\section{II) O caráter afetivo do conhecer: desejo e amor}

Leão Hebreu divide sua obra em três diálogos, que apresentam como interlocutores Fílon e Sofia. Sofia representa a própria sabedoria (a sapienza), já Fílon se põe como a

\footnotetext{
${ }^{2}$ Cf. FESTUGIÈRE, J. La philosophe de l'amour de Marsile Ficin. Paris: Vrin, 1941.

${ }^{3}$ Cf. KRISTELlER, P. Tradição Clássica e Pensamento do Renascimento. Trad. port. Artur Morão. Lisboa: Edições 70, 1995, GARIN, E. La Cultura Filosofica del Rinascimento. Roma-Bari: Laterza, 2010. ${ }^{4}$ Cf. CARVALHO, J. Leão Hebreu, Filósofo. Para a história do platonismo no Renascimento, p. 189: "O pensamento de Leão Hebreu não tem a espontaneidade nem a originalidade de alguns pensadores (...)".

${ }_{5}^{5}$ Cf. ARIANI, M. Imago Fabulosa. Mito e Allegoria nei Dialoghi D'Amore di Leone Ebreo. Roma: Bulzoni, 1984.

${ }^{6}$ Sobre a mistura entre lúdico e especulação filosófica nos diálogos renascentistas, ver aqui: PUGLIESE, O. Il Discorso labiríntico del dialogo rinascimentale. Roma: Bulzoni, 1995.
} 
razão demonstrativa ${ }^{7}$. Refletindo exaustivamente sobre a essência do conhecimento, Fílon não se satisfaz com a aquisição do saber. Algo lhe falta para que possa estabelecer vínculo unitivo, que ultrapasse os limites da dualidade. Por isso, sôfrego, voltando-se para Sofia, se inquieta, pois apenas a contemplação não lhe garante quietude. O mero conhecimento de Sofia não lhe dá o repouso, ou seja, não lhe garante um conhecimento unitivo, posto que é possível conhecer, sem estabelecer uma relação de unidade plena com a coisa conhecida. Permanecendo em uma relação dual, na qual se opõe cognoscível e cognoscente. Com efeito, a partir das exposições de Fílon, poder-se-ia indagar: se nem todo conhecimento é unitivo, que tipo de conhecimento se põe para além de simples ato intelectivo não unitivo?

Conforme se argumenta no primo diálogo, deve-se, pelo menos de início, aceitar que o intelletto sozinho não possibilita a suprema unidade. Isto é, como simples atividade intelectual, desprovida de qualquer caráter afetivo. Como já se entrevê na sofreguidão de Fílon, conceber o conhecimento desse modo, se não é algo inteiramente falso, não deixa de ser incompleto, uma vez que não compreende o conhecer em sua imanência, mas somente como modus operandi do intelecto. Somente o amor, segundo Leão Hebreu, é capaz de estabelecer um conhecimento perfeito, pois unitivo. Realização última da unidade entre pensante, pensado e pensamento, proporcional à tríade entre: amor, amado e amante. $\mathrm{O}$ amor se apresentando como gozo máximo de fruição, que nunca se separa do conhecimento prévio e da existência atual do objeto amado. O amor requer sempre um objeto em ato.

Ora, a atualidade da coisa amada é confirmada pelo intelecto. Assim, o amor supõe o conhecimento da coisa amada, todavia o conhecer não é o fundamento do amor. Este se põe para além das relações causais dos atos da intelecção. Contudo, se o conhecer antecede o amor, há outro tipo de conhecimento que se efetiva depois das operações do intelecto, trata-se de um conhecimento causado pelo amor. Um amoroso conhecimento. Não seria este conhecimento que justamente principia os Dialoghi, com a seguinte afirmação de Fílon: “O conhecer-te, Sofia, causa em mim amor e desejo

\footnotetext{
${ }^{7}$ Sobre as diversas hipóteses acerca dos nomes e o que representam Fílon e Sofia no decorrer dos diálogos, veja-se: Di CARPEGNA, E. Inseguendo Sofia. Filosofia e Amore sulle tracce di Leone Ebreo. Ferrara: Nuove Carte, 2010.
} 
(...)"8. Logo, em um primeiro momento, o conhecer implica necessariamente um caráter afetivo: amor e desejo vinculados.

Objetivando-se explicitar a diferença entre desejo e amor, deve-se considerar que, entre eles, o conhecer estabelece uma relação recíproca: quanto mais se conhece, mais se ama e se deseja. No caso de Fílon, não se trata de qualquer conhecimento, mas da própria sabedoria: contemplação desejante de Sofia.

A sapiência é o hábito das duas em conjunto (o entendimento e a ciência), de princípio e conclusão de todas as coisas que tem ser. É a única que chega ao conhecimento mais alto das coisas espirituais. Os gregos chamam-lhe teologia, que quer dizer ciência divina, e chama-se filosofia primeira por ser princípio de todas as ciências: nela se atualiza nosso intelecto no seu último e mais perfeito ser'.

De acordo com a definição de Fílon, o intelecto, antes de se atualizar na sapiência, realiza um movimento que passa anteriormente pelo entendimento e pela ciência. Aquela apreende os princípios do saber, porém com base nos impulsos naturais para os quais tendem todos os seres animados. Identifica-se, pois, com a potência intelectiva atuando em seu primeiro ser, o primeiro modo de conhecer. Já a ciência, estando entre o entendimento e a sapiência, é a mediania do intelecto. Ela abrange as setes artes liberais, procedendo por meio de premissas e conclusões. Afastada dos impulsos naturais, mas não possuindo os primeiro princípios, aqueles que dizem respeito à totalidade do ser, a ciência está a meio caminho entre a mera cognição natural e o conhecimento de Deus ${ }^{10}$. Mas que lugares ocupam o amor e o desejo nas atualizações do intelecto?

Leão Hebreu explicita que o amor não pode ser definido apenas como desejo de algo, nem tampouco, ser compreendido como uma espécie do gênero desejo. ${ }^{11}$ No caso de amor e do desejo, ambos possuem elementos comuns, contudo a distância entre os dois é loquaz. O desejar está para o não ser (carência), assim como o amor está para o ser (completude). Portanto, em um primeiro momento, são contrários, visto que um é presença de ser, o outro é falta de $\operatorname{ser}^{12}$.

\footnotetext{
${ }^{8}$ Cf. Leone Ebreo. Dialoghi d'amore. Lisboa: Instituto Nacional de Investigação Científica, 1983, p. 3.

${ }^{9}$ Ibidem, p. 90.

${ }^{10}$ Ibidem, p. 90-91.

${ }^{11}$ Ibidem, p. 63-67.

${ }^{12}$ Ibidem, p. 66: “Fílon - Se o amor não é senão das coisas que têm ser, por que delas não será também o desejo? Sofia - Porque, tal como o amor pressupõe o ser das coisas, o desejo pressupõe a privação delas"
} 
Se por um lado, o conhecer guarda uma relação necessária com o amor, ele também apresenta um vínculo de necessidade com o desejo. A definição primeira de conhecer, por princípio, não é outra senão desejo de saber, posto que o conhecer também é constituído pela carência, tal como o desejo ${ }^{13}$. Aquele que conhece, o faz em virtude da falta de algo: uma não atualidade do intelecto. Assim como o desejo demanda um elemento faltoso na atualidade do momento em que o desejoso expressa sua carência, assim também o conhecer no momento inicial das operações intelectuais. Quem busca conhecer está movido pela falta de algo que lhe satisfaça, ou seja, está marcado pela privação. Se o desejo é padecimento naquele que deseja, o momento inicial do conhecer é padecimento do intelecto: quem conhece, deseja alcançar algo que lhe falta. Do contrário não haveria movimento em busca da satisfação que se dá no conhecer. Todo conhecimento, sendo busca de satisfação, é também desejo. Nesse sentido, o movimento inicial do intelecto inicia no vazio, posto que privado, não atual. Todavia, é esta carência de ser que principia e incita todo ato intelectivo. Tal se identifica em Fílon: quanto mais conhece, mais deseja e ama.

Sendo o conhecer um ato não desprovido de desejo, poderia ele realizar a unidade perfeita, dissolvendo a tríade: pensamento, pensado e pensante? Movimento que se realiza no momento inicial do conhecer, na necessidade de um objeto externo que satisfaça a potência do intelecto. Não há ato de conhecer sem um dos três elementos da relação. Pode-se ao máximo conceber apenas dois elementos, desfazendo-se a tríade inicial. No pensar que pensa a si mesmo se efetiva um movimento imanente do pensamento que não se volta para nenhum objeto externo. Satisfazendo-se com e no seu próprio ser. Este movimento imanente, contudo, também pode ser concebido como desejo, porém desejo que se satisfaz em um conhecimento de si. A carência que marca o desejo, nesse caso não é suprida com algo externo, mas em um movimento contrário: o voltar-se para si. Ora, o que satisfaz a si mesmo apresenta certa perfeição, pois não demanda algo que se encontra fora de seu ser. Nesse sentido, não há certamente um desejo, no sentido forte do termo, mas uma autossatisfação gestada na contemplação de $\mathrm{si}^{14}$.

Todavia, no pensamento que pensa a si mesmo, se mantém ainda a dualidade, pelo menos na expressão da relação. Uma vez que o pensamento, tanto pode ser

\footnotetext{
${ }^{13}$ Cf. Leone Ebreo. Dialoghi d'amore, p. 64-66.

${ }^{14}$ Ibidem, p. 215: "A minha mente, aborrecida com os afazeres mundanos e com a necessidade de tão baixos exercícios, se recolhe em si própria como refúgio".
} 
designado por pensante, quanto por pensado. Aspecto dual que se mantém na própria fórmula: "pensamento do pensamento". Daí, ser necessário, mais uma vez, pensar um tipo de relação realizadora de unicidade plena, eliminando qualquer vestígio dual, até mesmo na expressão.

$\mathrm{Na}$ compreensão da operação do intelecto humano, deve-se salientar certa imperfeição do mesmo. O conhecimento humano sempre começa seu movimento operativo com uma carência inicial. Esta, para além do caráter negativo de toda privação, ativa as potências intelectivas, à medida que sua realização, na direção do seu fim natural, submete aqueles objetos, passíveis de predicação, à ordem do pensar. Conexão entre a ordem do pensar e a ordem das coisas. Sem desconsiderar que sendo próprio do conhecer realizar-se pelo pensar, também lhe é próprio o desejo, pois conhecer é desejo de saber. Todo e qualquer ato de conhecimento humano porta em sua gênese um caráter afetivo. Com efeito, a atividade intelectual não é somente movimento do intelecto, mas também disposição natural afetiva na forma de desejo.

Assim, nenhum ato de conhecer está completamente desprovido de caráter afetivo, não pode estar subsumido em um modo de operação estritamente "intelectualista". Nascendo do desejo e como desejo, e sendo próprio do desejar a falta (carência de ser), o conhecimento tanto dos entes, quanto de Deus apresenta, pois, uma imperfeição congênita ${ }^{15}$. Ora, um desejo satisfeito leva a outro desejo, em uma sucessão infinita. O desejo nunca cessa, pois é de sua essência a incompletude: todo desejo, uma vez satisfeito, já não é mais desejo. Assim também ocorre ao conhecer: um conhecimento adquirido, demanda a aquisição de outro. Tal como são infinitos os desejos, também infinitos são os cognoscíveis. A ordem dos desejos e das coisas desejadas parece não cessar. O cessar do desejo poderia se realizar apenas na medida em que o homem desejasse e se satisfizesse com um objeto, de tal modo perfeito e absoluto, que o completasse tão perfeitamente, de modo que não fosse possível mais nenhum resquício de desejo. Entretanto, a experiência ordinária mostra que tal feito parece impossível.

O conhecer, desprovido da potência amorosa, pode gerar um desejo sedento infindável. Leão Hebreu concordando, ao tratar da natureza do desejo, sustenta que:

\footnotetext{
${ }^{15}$ Cf. Leone Ebreo. Dialoghi d'amore, p. 93: “(...), pois o nosso conhecimento é menor que uma gota de água em comparação como todo o mar oceano".
} 
(...) tem diversos e infinitos desejos, e quando cessa um pela aquisição, outro sobrevém, maior e mais sôfrego, de tal modo que nunca saciam sua vontade de semelhantes desejos, pois quanto mais possuem, mais desejam, assemelhando-se àqueles que procuram matar a sede com água salgada, a qual, quanto mais a bebem, tanto maior é a sede que neles produz ${ }^{16}$.

Desejar e conhecer antecedem o amor no alcance da plena realização da unidade, pois dirigem-se à ausência, enquanto o amor exige a presença. Daí ser impossível amar aquilo que não se conhece, assim como também é impossível desejar aquilo que minimamente não se mostra conhecível, capaz de preencher a carência.

Assim, é próprio do desejar e do conhecer estabelecerem uma relação recíproca. Entre ambos, todavia, não se pode confundir a privação, fundante do desejo, com o nada. Privação de ser e nada não são sinônimos. Pois, ainda que o conhecer seja desejo de saber, a causa do conhecer não pode ser o nada. Do nada, e no nada, nada se funda: nihil ex nihilo fit. A privação de ser no desejo é uma não atualidade, uma incompletude, porém não um nada: não se tratando de uma total ausência de ser. Já que a própria falta no desejo deve se manifestar, pois sem tal manifestação não há desejo. Daí a natureza paradoxal do desejo: deve mostrar a falta por meio da presença. Não nascendo do nada, nem ao nada tendendo, o desejo busca a passagem do incompleto ao completo, do imperfeito ao perfeito, tal qual o conhecer que vai da potência ao ato na intelecção. Na discussão da relação entre ser e privação, conhecer e desejar, Sofia argumenta que:

Sofia - Não se pode negar que o conhecimento precede o desejo. Mas antes diria eu que todo conhecimento não visa apenas as coisas que são, como também aquelas que não são, porque nosso intelecto julga uma coisa, que é, como a julga, e assim outra que não é. E como seu ofício é discernir no ser e no não ser das coisas, é preciso que conheça aquelas que são e aquelas que não são. Eu diria, portanto, que o amor pressupõe o conhecimento das coisas que são, e o desejo o das que não são e daquelas de que estamos privados (...).

Os três, portanto, se dirigem para as coisas que são. Contudo o desejo, pode-se afirmar, está abaixo do conhecer e do amor, pois, sendo movido pela privação, não garante vínculo de unidade, no momento em que se mostra apenas na privação da coisa almejada. O desejo está para a separação, assim como o amor e o conhecer estão para a união. Se dirigindo para aquilo que está em ato, porém ainda não possuído. Em verdade, o desejo expressa a não atualidade de algo, em concomitância com a possibilidade de

\footnotetext{
${ }^{16}$ Ibidem, p. 71.
} 
realização da potência, tal como acontece com o intelecto na definição do conhecer como desejo de saber. Enquanto o amar e o conhecer demandam um ser em ato. Este último requer as coisas que são, já o primeiro só se mostra na posse e completa presença da coisa, uma vez que é antecedido pelo conhecer. Antecedido pelo conhecer e se apoiando nele, o amor pode ultrapassá-lo, na medida em que, no gozo da fruição completa da presença do amado, se desfaz qualquer dualidade, pela potência unitiva amorosa.

(...) daí que, aumentando o conhecimento, aumenta o amor à Divindade conhecida. Ora, como a essência divina excede o conhecimento humano em proporção infinita, e não menos a sua bondade o amor que lhe consagram os homens, por isso fica ao homem que aspira à perpétua felicidade um desejo ardoroso e desmedido de aumentar cada vez mais o seu conhecimento e amor divino. Para o homem este aumento é sempre possível, da parte do objeto conhecido e amado, muito embora do seu próprio lado possa acontecer que tais efeitos tenham o seu termo em um grau que ele não seja capaz de ultrapassar, ou então que, mesmo depois de se encontrar no último grau, lhe fique uma sensação de desejo de saber o que lhe falta, sem nunca o poder conseguir, ainda que fosse bem aventurado, devido à excelência do objeto amado sobre a potência e o hábito humano. Contudo, esse desejo que continua a subsistir nos bem aventurados não dever causar mágoa por aquilo que falta, porquanto não está na possibilidade humana ir mais longe; antes proporciona ao homem imenso deleite o ter chegado ao extremo da possibilidade, quer no conhecimento, quer no amor divino ${ }^{17}$.

No gozo da presença da coisa amada, se desfaz todo resquício de dualidade, não restando distância ou dualidade para o amante e o amado. Aquele que conhece e ama, posteriormente ama ainda mais por conhecer, quer, pois, ser um com a coisa conhecida que não é mais objeto do intelecto, porém transfigura-se no próprio amado. $\mathrm{O}$ amante conhecendo a excelência da coisa amada se funde a ela no ato de fruição do gozo amoroso. Tão excelente é a coisa amada, excedendo o intelecto, que só por meio do amor se elimina a última dualidade e se ultrapassa a perfeição limitada do intelecto. Trata-se ao mesmo tempo de um gozo e de um arrebatamento, proporcionado pela potência do amado, Deus, e pela chegada do intelecto e do amor humano ao seu último nível de atualidade.

\footnotetext{
${ }^{17}$ Ibidem, p. 91.
} 